\title{
Post-Petroleum Security in a Changing Arctic: Narratives and Trajectories Towards Viable Futures
}

\author{
Brigt Dale \\ Nordland Research Institute \\ Berit Kristoffersen \\ UiT Arctic University of Norway
}

\begin{abstract}
In this paper we explore how post-petroleum security is continually shaped by both the micropolitical practices of everyday life as well as the changing geopolitics of energy landscapes. We focus in particular on the two-decade long struggle over access to hydrocarbon deposits outside the Lofoten, Vesterålen and Senja archipelago groups (LoVeSe), and show how local security perspectives permeate both national and international debates concerning the future of oil and the global climate challenge. These developments, we argue, are taking place in a paradoxical conjunction with Norwegian political establishment who along with the oil and gas industry insist on continued petroleum dependency as the only viable future. We further investigate how particular controlling measures have determined past, present and future narratives, and assess how alternative ideas that include multiple possible trajectories have found their way into national and global debates despite these efforts. The argument permeating this paper states that while oil remains a security concern to both proponents and opponents to oil development in the Arctic, the extent to which this situation is seen as a threat or a security provider varies greatly.
\end{abstract}

Keywords: post-petroleum; ontological security; Norway; Lofoten; Arctic; disruption; transformation; green transition

Responsible Editor: Margherita Paola Poto, UiT - The Arctic University of Norway, Tromsø, Norway.

Received: May 2018; Accepted: September 2018; Published: October 2018

\footnotetext{
^Correspondence to: Brigt Dale, email: bda@nforsk.no

(C) 2018 Brigt Dale \& Berit Kristoffersen. This is an Open Access article distributed under the terms of the Creative Commons Attribution-NonCommercial 4.0 International License (https://creativecommons.org/licenses/by-nc/4.0/), allowing third parties to share their work (copy, distribute, transmit) and to adapt it, under the condition that the authors are given credit, that the work is not used for commercial purposes, and that in the event of reuse or distribution, the terms of this license are made clear.

Citation: Brigt Dale \& Berit Kristoffersen. "Post-Petroleum Security in a Changing Arctic: Narratives and Trajectories 


\section{Introduction: Doing oil}

In 2009, Norway celebrated 40 years of oil and gas extraction. A commemorative anthology comprised of fiction, myths and reminiscences written by historians, journalists, celebrities and novelists re-established a fairytale narrative that has followed the industry since its inception. The title itself, We found $i t$, we found $i t,{ }^{1}$ paraphrases one of Norwegian folklore's most famous and popular characters, Askeladden - the story of a hapless young man who through his curiosity and tenacity gains fame and fortune by charming the princess and tricking the king into letting him marry her. ${ }^{2}$ The allusion to this fairytale figure suggests that the story of the Norwegian oil and gas industry and to Norwegians by extension embodies the same qualities as those presented in the fairytale. That Norwegians conquer nature and the treasures under the seabed is seen as something typically Norwegian. Likewise, in a 2005 television documentary celebrating Norway's hundred years of independence from Sweden, four decades of oil extraction (to that date) is presented as something emanating from specific Norwegian qualities:

“... (the ocean) has taught the Norwegian (Nordmannen) that no life exists without hardship, no happiness without suffering." 3

Extend the Askeladden metaphor with perseverance and a sense of being a provincial outpost in modern Europe, and the backdrop for the Norwegian fairytale is set. Finding black gold is the ultimate triumph. The celebratory texts of the 2009 anniversary anthology was preluded with an introduction by then Prime Minister Jens Stoltenberg. He focused on employment and revenues generated from the oil industry and the specific global responsibility of Norway as a provider of energy to the world:

Through being a stable and predictable provider of oil and gas to international markets, we contribute to energy security both regionally and globally. (...) We cannot choose between energy or (the) climate, we must choose both. (...) The technological basis for the Norwegian petroleum industry gives us the opportunity to contribute to solving the challenges of a warming climate. The discharge of greenhouse gases from the [production at the] Norwegian shelf is amongst the lowest in the world. Technology developed at the Norwegian shelf contributes to a lower release of climate gases [from production, our insertion] than in other countries. ${ }^{4}$

Three years later, Stoltenberg stated that he had no idea what Norway would do 'after oil', as it would seemingly last another "...fifty to a hundred years...", and that those who were talking about a time after oil were "... well paid to present rubbish..." ${ }^{5}$ At the time, the Prime Minister promoted research and science as a way forward to enable enhanced extraction techniques. The outsider Askeladden had become King, and the King had no intention of risking his kingdom to mere speculation. The mythical past (finding oil) was thus coupled to a particular technoscientific rationale of practicing extractivism. This narrative supported the rationale 


\section{Brigt Dale E Berit Kristoffersen}

of governing offshore hydrocarbon spaces as a source of future economic security and simultaneously as a means of mitigating human induced climate change (as Norwegian oil was depicted as 'greener' than the global average ${ }^{6}$ ). This rationale dominated discourses on the future of Norwegian oil during the first fifteen years of the 2000 s.

\subsection{Polar Pioneering}

Of the seven thousand oil platforms scattered across the world, one more than any other symbolizes the ups and downs of Arctic and Norwegian oil futures: the canary yellow exploration rig Polar Pioneer. The name is not coincidental; it was built in the early 1980 s to deal with subarctic environments, extreme cold and high waves. Dubbed the "North-Norwegian Platform" in the 1980s because of its role in early exploration of the Barents Sea and its Tromsø-based ownership, it has been especially important for Equinor (Statoil until 2018) ${ }^{7}$, notably with the discovery of the Johan Castberg field in the Barents Sea in 2011.

But the Arctic Canary has been elsewhere as well. In May 2015, Polar Pioneer was surrounded by environmental activists in kayaks as it entered Puget Sound headed for Seattle. The Seattle City Council had voted against the entrance of the platform and civil resistance was strong. Shell, who had leased the rig, admitted that they were taken by surprise by the confrontation. Shortly after, Shell cancelled plans to drill in Alaska. Thus, it became world famous for the wrong reasons for Shell. For Arctic drilling, the Polar Pioneer came to symbolize failed exploration campaigns in Alaska, instead of the subordination of the northern seascape to human ingenuity and control over nature. More generally, it reflected the end of the expectation that the Arctic would become the new 'Middle East' in terms of abundant reserves, especially in the Barents Sea, where expectations have so to speak 'vanished'. 8

The viability of potential oil fields in the Barents Sea plays into Equinor's narrative of the region as the 'workable Arctic'. According to the company, in this space extraction solutions can be based on "... known technologies, and any remaining technology needs are within reach in the short to medium term". ${ }^{9}$ Emphasizing this understanding of the Barents Sea as the 'workable Arctic', makes a distinction between the Barents and more challenging parts of the Arctic, like the coastal waters off Alaska, defined as the stretch Arctic “... (requiring) major innovation but could be achievable with focused investment in the medium to long term". ${ }^{10}$ This division of the seascape into the 'workable', 'stretched' and - on a longer time scale - the 'extreme Arctic' (in need of a long-term focus and investments in technology) feeds on and strengthens the political viability of a scenario depicting an Arctic oil boom. Moreover, the geopolitics of the Arctic as a fossil fuel energy landscape also include a worst-case scenario where an Arctic oil race would unleash a scramble for the Arctic. As Norway's most important high north motivation was new energy resources, Norway positioned itself to take a leading role amongst the Arctic states in pushing 


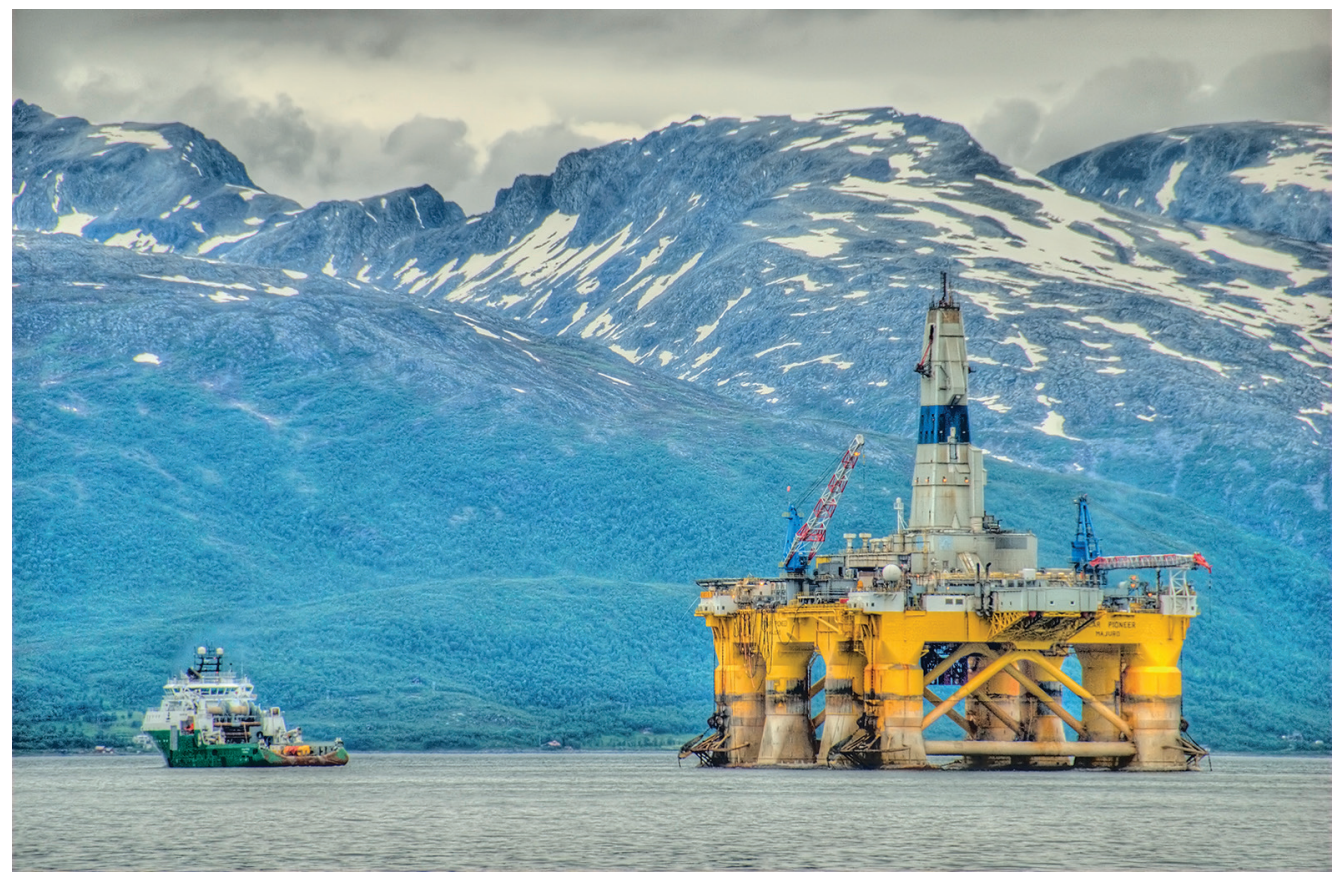

(Illustration 1. The Polar Pioneer, symbolically yellow as a Canary bird - both a materialization of the idea of a petroleum-driven perception of Arctic futures and a symbol of the heightened risk associated with large-scale investment in extractive projects in the region. (Photo: Per Ivar Somby, 2011. Used with permission).

northward. ${ }^{11}$ The underlying narrative here is clear: get there first or miss the final opportunity to exploit large, new areas for drilling on the Norwegian shelf; in other words, a race to the bottom where arguments concerning Norway's ability to secure so-called green oil to the world and natural gas to our European allies took center stage.

Thus, in May 2017, following a government-led program mapping oil and gas prospects on the Norwegian continental shelf, the Norwegian Petroleum Directorate (NPD) doubled their assessment of potential petroleum revenues in the Barents Sea. ${ }^{12}$ This new assessment included the Barents Sea North. This was a bold move, as this seascape partly includes off-limit areas north of the marginal ice zone (the so-called "ice edge"), an area identified in a plethora of research articles and reports as highly vulnerable and valuable for the ecosystems of the Arctic. ${ }^{13}$ After mapping the Barents North through seismic surveys and shallow explorations, the NPD estimated that the Barents Sea could hold 65 percent of the undiscovered oil and gas reserves in Norway, in effect redefining its importance and including it in the viable future of 'the oil' in Norway.

Even though assessments vary, there is general consensus that global investments in oil exploration have fallen sharply since the oil price fall in $2014 .{ }^{14}$ Canada and 


\section{Brigt Dale E Berit Kristoffersen}

the US ${ }^{15}$ have put a moratorium on Arctic drilling due to a mix of environmental concerns and an assessment of risks tied to production costs. Russia's activities have been modest, and new Arctic offshore developments have been put on hold until at least 2020 based on economic reasoning. There is also a standstill in initial exploration in Iceland and Greenland due to plummeting oil prices and heightened risks associated with investing in 'immature' regions. At present, the Arctic seems to be in an unfavorable position vis-a-vis potential new oil and gas prospects in other parts of the world, including unconventional fossil fuels in the US, which are making a comeback. This leaves Norway, represented by the Norwegian Petroleum Directorate and state-controlled Equinor, as the de facto petroleum polar pioneer. Not only does Norway see Arctic reserves as both lucrative and desirable, it has acted upon this belief. Still, after drilling around 170 exploration wells, only one gas field (Snow White) and one oil field (Goliat) have been developed, and seven years after the prospect fohan Castberg was discovered by Polar Pioneer, Equinor has still not finally decided how it will invest in its development. In the meantime, the government has been in the process of licensing about 150 new exploration blocks since 2015. As the state covers 78 per cent of its costs through the taxation system, one could say the effort - and risk - surely is as economical as it is political for the government and thus for the Norwegian population. It remains to be seen whether these prospects will meet the expectations of oil and gas actors and play a key role in maintaining the long-term profitability of the industry - or if they will end up in a category defined by the Norwegian Petroleum Directorate as 'will never be drilled'. Scrapping plans to develop these Arctic fields would mean a more sudden beginning of the inevitable end of the Norwegian petroleum era than anticipated just a few years ago.

As these introductory stories exemplify, the linking of a mythical Norwegianness to the extraction of oil permeates discourses on its past, present and future. Coupled with a techno-scientific rationality, this narrows the space for alternatives, and thus defines the parameters within which the political space for 'the oil' is negotiated in Norway. We therefore, after a presentation of the theoretical framework for our analysis in section 2, turn our attention in section 3 to another environmentally sensitive region (as defined in the Management Plan for the Barents and Lofoten Seas) - the rich fishing grounds surrounding the Lofoten islands in the southern parts of the Norwegian Arctic. What kind of narratives and practices are unravelling there, and how do these include considerations of potential future trajectories beyond polar pioneering?

\section{The past, present, and future of oil as a security concern}

Narratives about the Norwegian oil ontology is, we claim, a matter of ensuring a sense of ontological security in the national population. We have found that the way the concept ontological security has developed, from a focus on the state as the main security provider to a broader understanding of what - and who - provides 
security for populations, has opened for pertinent ways of discussing the relationship between institutions, epistemic communities and local stakeholders for this case, not least with respect to the ways in which a conformist understanding of ontological security blurs power relations and inclusion/exclusion processes concerning who is secured by which measures. ${ }^{16}$ Starting with a definition of ontological security proposed by Anthony Giddens as "...the confidence that most human beings have in the continuity of their self-identity and in the constancy of their social and material environments of action", ${ }^{17}$ we argue that a broadened focus on acts and actors influencing the ontological security ramifications of the potential future of Norwegian Arctic petroleum enables us to analyze how specific narratives evoke a connection between identity ('who we are') and extractive strategies ('what we do'), and how these narratives evoke a sense of inevitability with respect to a petroleum driven future, supported by technological development and a scientifically-based mastery of nature. Just as Veland and Lynch find that narratives about nature constructed by (and from) science are foundational for the sake of securing continuity in one's surroundings (2016), ${ }^{18}$ we find that stories constructing a sense of the naturalization of competence relevant for petroleum extraction embedded in the 'Norwegian' identity matter when decisions are made concerning how the nation state can best provide security for the Norwegian population. As they argue, "Myths fill gaps in understanding, implicitly staging desired outcomes and alternatives". ${ }^{19}$

There is, in other words, a combination of techno-scientific bravado and a sense of a naturalized way of being Norwegian that sustains the Norwegian petroleum fairytale narrative. However, the matter of sustaining (or securing) a population based on an extension of the realm of oil and gas - both in time and space - suffers from a lack of processual understanding of sustainability - and thus of long-term security needs. Instead of the dominant threshold- and endpoint-based assessments of risk and potential benefits from a continued 'extractivist' ideology, studies have shown that a circular modalities and multiple sustainabilities approach is needed. In order to face the multiple challenges ahead, ${ }^{20}$ not least those pertaining to the future need for energy, ${ }^{21}$ loss of biodiversity, ${ }^{22}$ dependence on non-renewable minerals ${ }^{23}$ and access to means of food production for future generations, we draw on Rossdale's assessment of the ontological security framework. ${ }^{24}$ This reflects how securing the population through the oil ontology may in fact increase a sense of future ontological insecurity. The reason to opt for a continued reliance on oil and gas is at least partly based on the conundrum that radical change is more often seen as a threat than something desirable - even though it is meant to secure against well-documented and defined threats such as the effects of global climate warming. ${ }^{25}$

Because adding to the list of uncertainties, indeed insecurities, is of course climate change. As its consequences surface - not only direct impacts to the well-being of populations, but also its effects on policies, finance, technology and ontologies - new paradigms arise. Trajectories that reference past experiences without acknowledging the unpredictabilities that signify rapid, non-linear and abrupt change increase 


\section{Brigt Dale E Berit Kristoffersen}

insecurity, and unfortunately for Norway, expose the vulnerabilities of being an oildependent society. Previously, risk assessments have primarily focused on technological risks concerning search and extraction; environmental risks primarily tied to the potential for local or regional negative effects; and financial risks mainly based on assessments of oil prices being set primarily by upstream accessibility, not a potential fall in demand. Future risk assessments of further exploration and extraction should include new variables such as liability for future loss of lives and property due to climatic changes driven by the burning of fossil fuels, the potential financial risks tied to a tax regime in which the Norwegian state de facto invests in the potential for future revenues from risky and expensive petroleum extraction sites, and the risk of path dependency and 'lock-in'. As Veland and Lynch have pointed out, increasing ontological insecurity may very well lead to “. .. insistence on having the 'right' knowledge and connections, insistence on a particular narrative, while violently marginalizing others" ${ }^{26}$ a situation which they call the " $\ldots$ trap of ontological insecurity". ${ }^{27}$ This in turn might lead to fundamentalism, or what we here more modestly call path dependency and technological lock-in. In practice, this might entail processes that lead to stranded assets and carbon lock-ins through infrastructure developments. In short, mundane questions concerning how to make sure future investments have a sound long-term risk profile is pivotal when making long-term energy investments. ${ }^{28}$ For the communities taking the risk, adaptive capacities and resilience need to be sufficiently secured ${ }^{29}$ so that future capabilities for transformation are put in place. ${ }^{30}$ These considerations should, we argue, open up political space for disruptive ontologies, new ways of understanding the interdependency between surroundings and meaningful realities post-petroleum. ${ }^{31}$ The post-petroleum analysis outlined in this paper therefore presents and promotes discussions on how perceptions about the future include multiple understandings of viability, of well-being, and of the potential of multiple future trajectories. This contrasts with hegemonic narratives that claim rationality when depicting one possible future as the only plausible alternative. Supporters of a future dominated by new extractivism in the LoVeSe and Barents seas are still 'talking security'. The focus is still on a future enmeshed in oil in ways that presupposes the survival of the oil ontology well beyond the transformative stages into post-carbon futures. Choosing oil today equips you for the future, the argument goes:

\footnotetext{
If you choose petroleum, you choose a field that will be important for years to come. We know that 60 percent of the world's need for energy will be covered by oil and gas in 2040. Choosing petroleum is therefore to choose (i.e. do the right thing for) the future. I wish the media would communicate the long message, namely that petroleum is a part of the future, as is renewables as well. I will therefore advise young people to choose petroleum. ${ }^{32}$
}

But with volatile oil prices, national debates have shifted. Compared to narratives about future pathways presented only a few years back, there is a different future envisioned ahead. Trajectories are discussed with a greater sense of multiplicity, urgency and sincerity pertaining to the need for transformation (although these 
narratives are far from uncontested). In order to understand the manifestation of alternative trajectories as something new, it is important not to overlook the way local debates - not least in LoVeSe - have included alternative visions of future pathways. These open for a variety of potential futures post-petroleum that has already materialized over the past few years. This means that the potential of being included in the era defined by the oil ontology is becoming less relevant. What we find instead is a focus on a basis for alternative pathways to a future post-petroleum that lies - paradoxically, perhaps - in the past. We have previously analyzed how two resources petroleum and fish - are mutually exclusive in debates about oil drilling and the future in the Lofoten region..$^{33}$ They represent, put bluntly, two different worldviews upon which an ontologically secure future can be built. This reflects the idea that not only are there two oppositional alternative futures that lay ahead; one with petroleum and the other without, but also that there are two different approaches to the long-term post-petroleum security of the region, one local and one national, that cut across the pro/con-petroleum divide. In this hierarchy of security concerns, 'the oil' (as people in Lofoten call it) is a potentially calculable reserve, providing the state and its population with future wealth as a basis for (ontological) security. Even so, whilst these national mainstream perspectives reflect anxieties about whether these resources can be left in the ground if the welfare state is to be maintained, discussions in Lofoten also reflect considerations concerning when they can or should be extracted, focusing on the period of extraction as a passing phase that should not threaten the potential for a viable future - economically, ecologically, and physically and thus ontologically.

\section{Lofoten with or beyond oil}

Lofoten - or more precisely the joint Lofoten, Vesterålen and Senja regions (abbr. LoVeSe) - plays a key role when path-dependency and the future of hydrocarbons in Norway are discussed. ${ }^{34}$ For protagonists, access to the sea outside these regions for petroleum development is a vital part of the development of the 'workable Arctic' discussed above; a 'step by step' operational push northwards in which Equinor sees the oil and gas in LoVeSe as having a key strategic role for developments in the southernmost areas of the Barents Sea. Both LoVeSe and southern parts of the Barents Sea are believed to be technologically manageable. The threshold for access to these areas is thus thought to be created, not by 'nature' or a lack of human ingenuity a la Askeladden, but by politics.

This last description of LoVeSe is indicative of the need for the petroleum industry not to give up on their defining right to explore wherever they feel it is viable economically. This is backed by an NPD 2011 assessment that it contains 1.5 billion barrels of oil, which equals eight days of global oil consumption. This is one of the ways in which Lofoten is 'normalized' as a frontier carbon space in the global political economy, as a space-making process for viable Norwegian oil futures. 


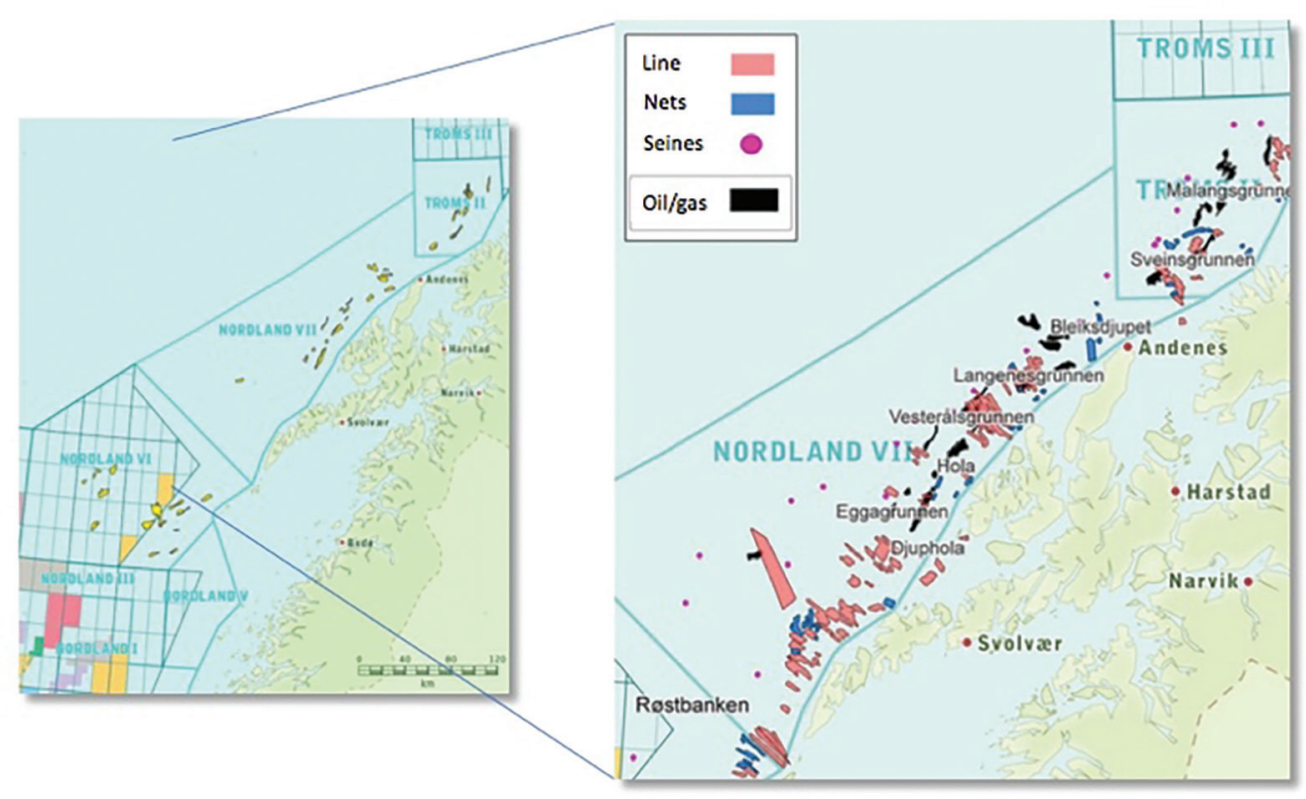

(Illustration 2. The constructed void in the map over sea areas outside LoVeSe from an oil ontology perspective (Ill 1), and the complexity of fishery and oil interaction (Ill 2)

(Graphics: Norwegian Petroleum Directorate (left) and Friends of the Earth Norway (right)).

It is pertinent to ask what kind of imaginaries are challenging this naturalization of a trajectory based on what we refer to here as the oil ontology, ${ }^{35}$ and what resilient and alternative visions and practices evoking disruptive ontologies are arising that might replace the one where the area is 'up for grabs'. Importantly, though, we also find it necessary to analyze how 'the ultimate, empty frontier' of LoVeSe and Equinor/Statoil's categorization of the southern parts of the Barents Sea as the 'workable Arctic' both play into narratives evoking policies of path dependency and a future in the north based on a hydrocarbon fueled economy.

An important premise for these narratives is found in the construction of specific parameters for the inclusion and exclusion of the knowledge deemed relevant for securing a petroleum-driven future. ${ }^{36}$ The act of extraction concerning both the LoVeSe frontier and the 'workable Arctic' category as defined by Equinor/Statoil is clearly an indication that as long as a techno-scientific assessment of possibilities are left to solve the problem of access to the petroleum riches, the areas are within reach. As claimed in Equinor/Statoil's own description of their Arctic strategies to peers in the online publication World Expro in 2017, it is a "mission possible" if left in the capable hands of engineers, geologists and petroleum analysts. ${ }^{37}$ The extractive industries hold on the political debate has dwindled though, as public awareness concerning the direct interlinkages between domestic petroleum development, future economic and ontological security and climate change has grown, a process 
clearly indicating that a platform for alternative visions of the future has begun to take hold even in national Norwegian politics.

Political debate in Lofoten has gone from a "conditional no" in the early 2000's pending considerations over fisheries, via a "conditional yes" in terms of statements about potential ripple effects around 2010, ${ }^{38}$ to an "unconditional no" in the present. In recent years, 'the oil' has largely been absent in local and regional debates about strategic economic development, as there are other more pressing issues in terms of economic opportunities. The oil ontology seems distant politically and geographically, reflecting the center-periphery axis of political power in terms of determining a viable future for northern communities. As a Lofoten merchant explained in July 2017 when the oil ontology came up in discussions over the counter in his store: "Lofoten is characterized by optimism; good times in the fisheries rubs off on other industries and the general atmosphere. In other words," he explained, "there is no room for oil here, not in terms of areas at sea, or in terms of development over the next few years". He repeated a sentiment often heard in the local debate: “... we should leave it to the next generations to decide". Exhibiting strong feelings about this issue, he said that even though he had never engaged in politics or conflicts, he would turn to civil disobedience and physically put himself in front of exploration platforms in the water if 'the oil' came to Lofoten ".. in the name of my (unborn) grandchildren". ${ }^{39}$ The political leverage of the fisheries has changed following economic growth in recent years, which is also reflected when key political figures come to Lofoten to promote oil futures. "Zero emissions with oil development," promised Prime Minister Erna Solberg when she visited Lofoten to promote oil development in the summer of 2018. She argued that "... past experience with co-existence between the industry and the fisheries indicates that it will work out". ${ }^{40}$ The CEO of the local fish processing company Insula, Sigvald Rist, responded by stating that "... the oil industry will be very damaging for us", referring not only to the potential for an oil spill (although the risk is minor), but also to the effects of seismic shooting that takes place in the fishing areas for weeks at a time, in effect stopping deliverance of fresh fish. He went on to reflect back to the summers of 2007 to 2009 when the Petroleum Directorate conducted seismic shooting in the LoVeSe regions:

"... the fishermen were paid to stay onshore. It is OK that the fishermen were paid, but industry on land did not get anything. We would rather make money on goods we sell." ${ }^{11}$

It is an oft-repeated paradox that whilst national political figures keep bringing up the matter of opening Lofoten for oil exploration and development again and again, the region has seen a veritable upsurge in innovation and entrepreneurship primarily based on one old and one new industry - fisheries and tourism. But there are also processes resembling those found in so-called creative cities or neighborhoods studied by urbanists (and mostly economists) ${ }^{42}$ - a string of new, small-scale businesses of numerous kinds, providing jobs for an increasing number of people choosing to live there because of the lifestyle the region enables them to pursue. In 


\section{Brigt Dale E Berit Kristoffersen}

short, whilst the debate over oil rages, ontological security is in the process of being created in the region bottom-up. For northerners, the oil and gas-driven development meant to foster ontological security is seen as irrelevant, perhaps even a disruption, a source of insecurity. In many ways, Northern Norway's local industries have experienced the opposite effects of the 'oil price shock' that has reverberated across the south. Exporting industries and tourism, have been given a boost as the Norwegian krone has weakened, in sync with the price of oil. This strengthens what we identify as a hierarchy of security concerns in Lofoten, where fisheries come first, and other existing primary industries related to food production come second along with a booming tourism industry. The potential extraction of oil and gas and with that the introduction of a new industry is considered of lesser importance, or even unimportant at the time of writing, in discussions of potential futures in Lofoten, a notion that is also reflected in a poll from the summer of 2017 where more than seven out of ten northerners did not want to open for oil development. ${ }^{43}$

As life goes on in Lofoten, without oil, it pivots around the fisheries and the ocean, culturally and socio-economically rooted in inherited practices with a mix of traditional and new knowledge and technologies, characterized by a particular sense of nature, of being-in-the-world, to paraphrase Tim Ingold. ${ }^{44}$ The question of oil in Lofoten stirs up as much insecurity over whether the region will be able to secure a meaningful future post-petroleum as it stirs up notions of prosperity and income, short term. In many ways then, what gets recognized as an asset in these seascapes reflects contrasting practices related to a long history of harvesting from nature, state oil ontology strategies and oil company exploration interests. Our attentiveness to an oil fueled future thus recognizes that it is based on an ontology of extraction that admittedly has provided economic security for the Norwegian state and its population in the past and the present. However, it will potentially trap Norwegian society in a developmental trajectory where potential alternatives for the future are excluded. As Canavan has noted, “.. in the era of oil ontology, oil becomes synonymous with progress, even with the future itself" 45 - the future imagined without an ontological shift risks becoming path dependent, unable to meet the challenges ahead. We therefore argue for a focus not only on disruptive technologies, but even more importantly on fostering disruptive ontologies, as the imagining of potential post-petroleum futures begins with paving multiple paths, multiple possible trajectories.

Another disruptive ontology apart from that based upon more or less traditional ways of harvesting from nature has manifested itself in the recent Lofoten Declaration. ${ }^{46} \mathrm{~A}$ number of global NGOs under the umbrella of labor, development, climate and environmental justice came together for a strategy meeting in Lofoten in August 2017 and called for a long-term moratorium on the Lofoten islands, where activists and scientists concerned with local, national and global environmental and climate threats challenged Norway to leave the oil in the ground to comply with the $2^{\circ} \mathrm{C}$ target from the Paris Declaration of 2015. A major motivation for the movement to choose LoVeSe as a key moratorium site was the potential of LoVeSe being the 'first 
win' in an ongoing struggle to leave oil in the ground and bringing it into the conversation at the Bonn Climate Summit in November 2017 (COP23). As observed by one of the authors who was present in Bonn, the signing of the Lofoten Declaration became one of the key NGO-driven events at the summit, as global NGO figures from both the global south and north gathered at the event to sign the declaration. It adheres to the discourse presented in a paper on the geographical distribution of unburnable fossil fuels by McGlade and Ekins which states that Arctic oil should be off limits based on the perspective that "... globally, a third of oil reserves, half of gas reserves and over 80 per cent of current coal reserves should remain unused from 2010 to 2050 in order to meet the target of $2^{\circ} \mathrm{C} .{ }^{\prime 47}$ The Lofoten Declaration states that inequalities within and between fossil fuel producing countries should lead to rich oil producing states like Norway leaving oil in the ground. Initiatives like this show that the bottom-up processes we previously have described in Lofoten (where local responses to top-down initiatives permeate politics ${ }^{48}$ ) has also reached the international scene, exemplified in alternative strategies for future climate policy design. Rather than responding to market-driven pressures associated with demandside initiatives (i.e. consumption), supply-constraint initiatives to limit production, as reflected in the Lofoten Declaration, can offer more direct and intentional options to current and future fossil fuel producers. As such, supply-constraints offer a geopolitical economic 'space' of purposeful political intervention that can help manage the economic (and political) fallouts of a transition away from fossil fuels. ${ }^{49}$ Thus we posit that the post-petroleum argument, in which we describe ways in which alternative futures envisioned from below may have transformative power, is strengthened by observations of developments after the 2014 oil price crash described here, with pressures to take on global responsibilities.

\section{Lofoten, the problem of oil - and oil's big problem \\ "... oil is (...) ontology, the structuring 'Real' of our contemporary sociopolitical imaginary" 50}

"Oil as hyperobject", Gerry Canavan writes in the anthology Oil Culture, "delimits our ability to both understand our historical past and imagine our possible futures, becoming the secret subtext of any number of futurological imaginings." ${ }^{\text {51 }}$ In the foreword to the same anthology Allan Stoekl describes oil as "... the ultimate culturalnatural artefact". ${ }^{52}$ Barrett and Worden identify oil as the hub in a

... vast network or "assemblage" of interlinked technological, commercial, financial, and political initiatives. (...) We are the slaves of our energy - slaves in a surprising revision of the Hegelian master-slave dialectic. We work to further oil's consumption, imagining ever more wasteful "uses" for it - from lavish oil-heated homes to gas-guzzling Hummers. We cannot help to realize that in some sense we are oil: all those grain-fed cattle we eat, themselves fed with cereals grown with fossil-fuel - derived fertilizers and protected by oil-based pesticides; all the water purified and pumped with the use of fossil fuels; 


\section{Brigt Dale E Berit Kristoffersen}

all the wars powered and won with fossil fuels - not least all the wars for control of oil resources. And we are the disappearance of oil. We are human, social, cultural - that is, we are not formed by a god, we form, make, ourselves - but we are also what we have done with oil. And oil is natural in the sense that it is present, then absent: it is finite, and that ultimate finitude is well beyond our control. ${ }^{53}$

No less. The idea that we can solve how to live without oil through seeing oil as part of the solution to the challenges represented by the warming of the planet may seem illogical, but evidently it is imaginable, not least through abstractive practices delineating the basis for policy making in a transformation era to the parameters of an oil ontology $y^{54}$; a world where nothing happens, nothing develops, without oil. What a focus on a solution to the utilization of fossil fuels using fossil fuels reveals, then, is a matter of endpoint vs process; as endpoints close to - for instance 2040 or even 2100 - are meant to put a focus on the need for action, the result is often that the consumption of fossil fuels is provided at that exact endpoint a space in which to maneuver; a room for utilization within predefined parameters of a techno-scientific assessment of acceptable risk. ${ }^{55}$ Therefore, the argument is that the only possible future (at specified endpoints, like 2040) is one where oil still occupies a significant space, as - again - “.. the subtext of any futurological imaginings", as quoted from Canavan above.

Another factor hampering the imagining of alternative futures - except, obviously, the highly unpleasant prospect of the public having to deviate from a petroleum-driven economy, which explains the electoral gridlock on making climate change an issue that truly matters when ballots are cast - is the way in which a focus on disruptive technologies without attending to the need for ontological reorientation or disruptive ontologies (see above) dominates strategic discussions on how to ensure that Norwegian society is provided with the necessary transitional capabilities. The path on which most walk is one where the transition of technological know-how from the petroleum industry to new, emerging, greener technologies is a core strategy, a strategy that can only work, it is argued, if the petroleum industry is provided with new opportunities - and challenges - where technological innovation is needed. Consider for instance the Barents Sea or the vulnerable LoVeSe areas. It is argued that technologies to be invented in the future will secure revenues from expected oil and gas fields in these regions, and will also be the basis for the technology that will ensure a transition to a low-carbon - and then (sometime in the undefined future), a no-carbon future. Therefore, the logic goes, we need big oil - and the capabilities, tenacity and ingenuity of the technologists that support it - to get to post-petroleum society.

A final point to be made which influences the current debate on alternative futures is that oil is not only the problem - it is in deep trouble itself, de facto losing its value as a long-term reserve for producers. Indeed, the industry and its protagonist's hegemonic position in defining the parameters for discussing the future is, as mentioned, waning. Even though oil prices have risen since the 2014 crash, and expenses in the industry have driven down the break-even point, the fact that American shale 
oil has introduced an endemic imbalance in the developed checks-and-balances system of international oil trade has made debaters in Norway acutely aware of the heightened risk profile of future petroleum investments in the north, and 'after-oil' scenarios are being discussed with greater urgency today than just a couple of years back - with a particular focus on the Lofoten area as a first site for leaving oil in the ground. As the size of the market for oil is likely to decrease, again due to competing energy sources and electrification of the transport sector, the most technologically challenging and economically pricy projects will lose in the end. This is also a reason why the Norwegian petroleum industry wants a carbon tax; assuming that there will be a need for a certain amount of petroleum in the future, the matter of who will produce and sell it is imperative for the future prospects of the industry, both globally and in Norway. A global carbon tax would surely be beneficial for Norwegian oil and gas, as a national tax was implemented 25 years ago and competition with others would greatly improve if other actors also had to pay for polluting while producing.

\section{Summary Remarks}

Challenging the oil ontology - the world view - upon which arguments for the continued expansion of oil and gas extraction northwards, into unchartered waters both geographically and metaphorically (as technological risks are combined with new levels of financial, political and scientific insecurities) are in our opinion of utmost importance, if we are to ensure a pluralistic approach to the multifaceted challenges of the future. Surely, increased awareness of the heightened risks connected to the expansion of oil and gas development northwards has begun to manifest in political discourses and in more forceful counter-argumentation to the oil fairytale narrative. During fieldwork only a few years back, we would meet national oil executives on tour in northern Norway seeking local support for the expansion northwards who blatantly disregarded opposition as 'sentimentalism', based on 'emotions, not facts'. Today, most national petroleum executives take the opposition far more seriously and have co-opted discourses of climate change and concern for local and regional environmental risks. They also acknowledge the needs of other industries. Strategically though, they have seemingly turned away from the argument that petroleum development is primarily a source for development in the northernmost regions, and instead focus - as we have outlined - on the need for northward expansion for the sake of the future security of the Norwegian population.

Now 50 years after first finding it, Norwegians are forever tied to oil. Or so the story goes. But the past, in fact, reflects the passing quality of oil and its connection to a sense of collective, ontological security; just as it has delivered unprecedented wealth to the people of the Norwegian regions of Rogaland, Hordaland and Sogn og Fjordane - and, obviously, to the financial sector in Oslo - it will eventually wither away, thereby presenting us with a situation of potential ontological insecurity, not least as an imagined community secured by oil no longer feels home to all Norwegians. ${ }^{56}$ As we 


\section{Brigt Dale E Berit Kristoffersen}

have experienced recently, with the sudden and unprecedented plummeting of petroleum prices - the Norwegian petroleum industry is vulnerable to changes in the volatile international energy market, and there is a concern that we are in danger of implementing strategies where authoritarian notions of what secures the immediate and longterm future dominate. Contrary to narratives promoting the continuation of petroleum extraction northwards as a means of securing the future, oil will not last forever, and the energy industry will eventually change beyond adaptation, away from fossils. But for now, narratives that insist that oil will provide ontological security into the future have adopted the climate change political discourse, and manipulated emission models for hydrocarbon within a $2^{\circ} \mathrm{C}$ scenario for 2040 to show that their products can be a part of the future, and that oil and gas are part of the solution to the climate challenge..$^{57}$ However - trying to show that the source of the problem is part of a permanent solution is more difficult. Thus, the connection between petroleum and ontological security is surely a passing one for the Norwegian population - and one which eventually will turn on the industry as well, as their connections to "Norwegianness" no longer will hold merit as their presence in Norwegian politics, economy, and broader society shrinks. The worry, of course, is that with the current focus on being a part of the solution, a continued oil-driven economy and technological development will lead us too far down a path where a fossil epistemic community still dominates.

\section{ACKNOWLEDGMENTS}

The research upon which this article is based was in part collected and analyzed as part of the project ARCTICCHALLENGE:Arctic petroleum development as a challenge to societies: A comparative look at Norwegian, Greenlandic and US case sites, founded by the PETROSAM 2 program of the Norwegian Research Council. The corresponding author would like to thank all partners for their contributions to the project from which this article has benefited. We also want to thank the reviewers for comments and suggestions that strengthened our arguments and conclusions, and the copyeditor who surely made the paper more readable.

\section{NOTES}

1. Translated from the Norwegian phrase "Vi fant, vi fant".

2. Nebben, K. B., Ed. (2009). Vi fant vi fant. Norge feirer 40 år som olje- og gassnasjon. Oslo, Font forlag.

3. See https://www.youtube.com/watch?v=P-FMmsAehNc, translated by the authors. Accessed September 18, 2017.

4. Former PM Stoltenberg, in Nebben 2009, our translation.

5. Cited in https://www.tu.no/artikler/stoltenberg-jeg-vet-ikke-hva-vi-skal-leve-av-etter-oljen/ 321205, our translation. Accessed September 18, 2017.

6. See for instance Down, A., \& Erickson, P. (2017). Norwegian oil production and keeping global warming well below $2^{\circ} \mathrm{C}^{\prime}$. A discussion Brief. Retrieved from Stockholm: www. sei-international.org; Dale, B., \& Andersen, G. (2018). Til Dovre faller? Norsk olje og grønn omstilling. In H. Haarstad \& G. Rusten (Eds.), Grønn omstilling: norske veivalg. 


\section{Post-Petroleum Security in a Changing Arctic}

7. We will for the sake of consistency henceforth refer to the company with both names, thus: Equinor/Statoil.

8. Pedersen. T. (2018). Når Nordområdene lever sitt eget liv. Internasjonal Politikk 73 (3), pp. 140-158. doi: https://doi.org/10.23865/intpol.v76.1122

9. See Statoil (2014) "A responsible approach to Arctic operations" Online feature story in EU in the Arctic's information portal http://www.arcticinfo.eu/en/features/103-a-responsible-approach-to-arctic-operations accessed May 2018.

10. Op. cit.

11. Op. cit.

12. Seehttp://www.npd.no/no/Nyheter/Nyheter/2017/Dobler-ressursanslaget-for-Barentshavet/, accessed September 4, 2018.

13. See for instance Veland, S. and A. H. Lynch (2016). "Arctic ice edge narratives: scale, discourse and ontological security." Area; Steinberg, P. E. and B. Kristoffersen (2017). "The ice edge is lost ... nature moved it': mapping ice as state practice in the Canadian and Norwegian North." Transactions of the Institute of British Geographers.

14. For instance, a Forbes article from March 2018 estimates that US 1 trillion has been held back from oil investments in the period 2014-18, and that 25 percent reductions in investments in both 2015 and 2016 were followed by a mere 6 percent increase in 2017. See https:// www.forbes.com/sites/judeclemente/2018/03/08/the-continuous-need-for-new-oil-investments/\#1e9b52bd1efb, accessed May 2018.

15. When the US elected President Donald Trump in 2016, these policies immediately came into play, although thus far (2018), the consequences of reversing the moratorium has had little effect on offshore Arctic activities.

16. See Dale, B. (2016). Governing resources, governing mentalities. Petroleum and the Norwegian integrated ecosystem-based management plan for the Barents and Lofoten seas in 2011. Fournal of Extractive Industries and Society, 3(1), 9-16. doi:10.1016/j.exis.2015.10.002; Rossdale, C. (2015). Enclosing Critique: The Limits of Ontological Security. International Political Sociology, 9(4), 369-386. doi:10.1111/ips.12103; Norgaard, K. M. (2006). "People Want to Protect Themselves a Little Bit": Emotions, Denial, and Social Movement Nonparticipation. Sociological Inquiry, 76(3), 372-396.

17. Giddens op. cit.: 92.

18. Veland, S. and A. H. Lynch op. cit.

19. Op. cit: 3

20. Leach, M., et al., Eds. (2010). Dynamic Sustainabilities:Technology, Environment, Social fustice. Pathways to Sustainability. Sussex, Earthscan Routhledge.

21. IEA (2016). World Energy Outlook. F. Birol. Paris, International Energy Agency; IEA and IRENA (2017). Perspectives for the Energy Transition.

22. TEEB (2010). The Economics of Ecosystems and Biodiversity: Mainstreaming the Economics of Nature: A synthesis of the approach, conclusions and recommendations of TEEB, UNEP - United Nations Environment Programme.

23. Dale, B., et al. (2018). The Will to Drill. Mining and Arctic Communities. London, Springer.

24. Rossdale, C. (2015). Enclosing Critique: The Limits of Ontological Security. International Political Sociology, 9(4), 369-386. doi:10.1111/ips.12103.

25. E.g. Haarstad, H. and T. I. Wanvik (2016). "Carbonscapes and beyond: Conceptualizing the instability of oil landscapes." Progress in Human Geography; O’Brien, K. L. (2016). "Climate change and social transformations: is it time for a quantum leap?" Wiley Interdisciplinary Reviews: Climate Change. doi:10.1002/wcc.413; Norgaard, K. M. (2011). Living in denial: Climate change, emotions, and everyday life. The MIT Press.

26. Veland S and A.-H. Lynch op. cit.: 5.

27. Op. Cit.: 6. 


\section{Brigt Dale E Berit Kristoffersen}

28. Ansar, A., et al. (2013). Stranded Assets and the Fossil Fuel Divestment Campaign. Working paper. Smith School of Enterprise and Environment (SSEE)/ Stranded Assets program, University of Oxford.

29. Hovelsrud, G. K., et al. (2010). "Adaptation in Fisheries and Municipalities: Three Communities in Northern Norway." 23-62; Dannevig, H., et al. (2013). "Driving the agenda for climate change adaptation in Norwegian Municipalities." Environment \& Planning C: Government \& Policy 31(3): 490-505.

30. O'Brien, K. L. (2016). "Climate change and social transformations: is it time for a quantum leap?" Wiley Interdisciplinary Reviews: Climate Change.

31. Kristoffersen, B and B. Dale (2014). "Post-Petroleum Security in Lofoten: How identity matters." Arctiv Review of Law and Politics, 5 (2), pp. 201-226.

32. Ingvald Strømmen, professor and Dean of Faculty of Technology and Engineering, Norwegian University for Science and Technology (NTNU), to the Norwegian news agency e24. no, March 27, 2016.

33. Kristoffersen and Dale, op. cit.

34. See for instance Dale, B., \& Kristoffersen, B. (2016). Imagining a Post-Petroleum Arctic. Hot Spots, Cultural Anthropology website; Kristoffersen, B., \& Dale, B. (2014). "PostPetroleum Security in Lofoten: How identity matters". Arctic Review of Law and Politics, 5(2), 201-226; Hauge, K. H., Blanchard, A., Andersen, G., Boland, R., Grøsvik, B. E., Howell, D., Vikebø, F. (2014). "Inadequate risk assessments - A study on worst-case scenarios related to petroleum exploitation in the Lofoten area". Marine Policy, 44(0), 82-89. doi:http://dx.doi.org/10.1016/j.marpol.2013.07.008

35. Szeman, I. (2007). "System Failure: Oil, Futurity, and the Anticipation of Disaster." South Atlantic Quarterly 106(4): 805-823; Szeman, I. (2010). "The Cultural Politics of Oil: On Lessons of Darkness and Black Sea Files." Polygraph 22: 33-45.

36. Kristoffersen and Dale, op. cit.

37. See http://www.worldexpro.com/features/featuremission-possible-inside-statoils-arcticoperations-4543219/, accessed September 25, 2017.

38. Kristoffersen and Dale, op.cit.

39. Fieldnotes, Kristoffersen, August 3, 2017.

40. Thomas Rud 2018; Oljeindustrien vil være svært skadelig for oss, Avisa Lofoten August 25, 2018 https://avisalofoten.no/statsministeren-tror-pa-sameksistens-mellom-olje-og-fiske/25. 08-10:17 Retrieved September 3, 2018.

41. Op. cit.

42. See for instance Florida, R. (2011). The Rise of the Creative Class (Revisited: the 10th Anniversary Edition). New York: Basic Books.

43. See https://forskning.no/miljo-miljovern-olje-og-gass-samfunn/2018/01/i-nord-norge-erover-70-prosent-imot-oljeboring-i, accessed March 13, 2018.

44. Ingold, T. (2011 (2000)). The Perception of the Environment - Essays on livelihood, dwelling and skill. London, Routhledge.

45. Canavan, G. (2014). Retrofutures and Petrofutures. Oil, Scarcity, Limit. Oil Culture. R. Barrett and D. Worden. Minneapolis, University of Minnesota Press, p. 334.

46. Oil Change International (2017). The Lofoten Declaration: http://www.lofotendeclaration. org, accessed May 2018.

47. McGlade, C. and P. Ekins (2014). "Un-burnable oil: An examination of oil resource utilisation in a decarbonised energy system.” Energy Policy 64: 102-112, quote from p. 187.

48. Kristoffersen and Dale, op. cit.

49. Le Billon, P. and B. Kristoffersen (in review) "Just cuts for fossil fuels? Supply-side carbon constraints and geo-political economies of energy transitions", EPA: Economy and Space. 
50. Szeman, I. (2007). "System Failure: Oil, Futurity, and the Anticipation of Disaster." South Atlantic Quarterly 106(4): 805-823, quote from p. 34.

51. Canavan, G. (2014). Retrofutures and Petrofutures. Oil, Scarcity, Limit. Oil Culture. R. Barrett and D. Worden. Minneapolis, University of Minnesota Press, quote on p. 332.

52. Stoek1, A. (2014). Foreword. Oil Culture. R. Barrett and D. Worden. Minneapolis, University of Minnesota Press, quote on p. xii.

53. Barrett, R. and D. Worden (2014). Introduction. Oil Culture. R. Barrett and D. Worden. Minneapolis, University of Minnesota Press, quote on p. xxiv.

54. Szeman, op. cit.: 41 .

55. Examples of this are of course the way the petroleum industry has chosen to get in line on the issue of climate change, only to seek room for their products within scenarios predicting a need for a certain level of fossil fuel at any given time and still being able to mitigate climate change. See for instance Statoil's Energy Perspectives from 2015, 2016 and 2017, and the strategies presented in the roadmap for emission cuts from the Norwegian petroleum industry, downloadable (in Norwegian) here: https://www.norskoljeoggass.no/miljo/klima/ veikart-for-norsk-sokkel/, accessed May 2018.

56. See Rossdale (op. cit.) for a discussion of the inherent insecurity potential of creating homogenic ontological security entities for those necessarily excluded, a critique firmly rooted in recent debates over the dual role of identity politics.

57. In brief, the petroleum industry forcefully argues that their production of 'green oil' and particularly gas should be the last fossil fuel production to shut down. This argument is based on achieving the emission goals set by the IEA's 450 scenario, in which there is a 50 percent chance of reaching the $2^{\circ} \mathrm{C}$ target, presupposing amongst other things the broad global implementation of yet unsuccessful CCS (carbon capture and storage) technology. See IEA (2016) and Statoil's Energy Perspective reports $(2015,2016,2017)$, in particular. 